\title{
Gangs in Asia: China and India
}

\author{
Marek Palasinski ${ }^{1}$, Lening Zhang ${ }^{2}$, Sukdeo Ingale ${ }^{3} \&$ Claire Hanlon $^{1}$ \\ ${ }^{1}$ School of Natural Sciences and Psychology, Liverpool John Moores University, Liverpool, UK \\ ${ }^{2}$ Department of Sociology and Criminal Justice, Saint Francis University, Loretto, USA \\ ${ }^{3}$ DES's Navalmal Firodia Law College, Pune, India \\ Correspondence: Marek Palasinski, School of Natural Sciences and Psychology, Liverpool John Moores \\ University, Liverpool, L3 3AF, UK. Tel: 44-151-904-6304. E-mail: m.palasinski@ljmu.ac.uk
}

Received: March 30, 2016 Accepted: April 28, 2016 Online Published: July 7, 2016

doi:10.5539/ass.v12n8p141 URL: http://dx.doi.org/10.5539/ass.v12n8p141

\begin{abstract}
The problem of gang crimes dates back to the first cities founded thousands of years ago. Its traces can be even discerned in the draconian Hammurabi code of ancient Mesopotamia. To various extents and in many different forms, including muggings, pickpocketing, prostitution and turf wars, it has also plagued ancient Egyptian, Greek and Roman cities, giving ruling classes nightmares and heavily curbing the frequency of their evening walks. Today's cities across the world continue to be afflicted by them. Although today's gangs differ, in the increasingly globalized and interconnected world, they also share many characteristics, which have been explored in great depth and with a particular focus on the 'Western' culture. This relatively short review will cover the issue of gang crime in the rising superpowers of China and India. Given the scarcity of available data, it will be limited, but it is hoped that it will inspire further focus on these places that tend to be undeservingly ignored in the academic discourse of the West.
\end{abstract}

Keywords: gangs, crime, Asia

\section{Gang Crime in Contemporary China}

An online manhunt has been launched in China to try to track down four youth gang members who punched, kicked and threw a slab of rock at a defenseless lying teenager before urinating on his face. The 'happy slapping' attack, which apparently took place in Beijing and lasted over 5 minutes was then posted online, prompting the Ministry of Public Security to launch an official investigation.

Youth gangs and gang-related crime in China were not considered as social problems during the 1950s and 1960s because Mao's regime exerted strict political and social control. However, since the nation implemented its economic reforms in the late 1970s, youth gangs and gang-related crime have been on the rise. The gangs have also been associated with the changing reality of youth offenses in China since the 1980s. The official statistics indicate that from 1991 to 2001, the number of reported juvenile delinquents increased from 33392 to 49883 and had a sharp increase to 70086 in 2004 (Luo, 2007). As youth offenses increased, so did youth gangs and gang-related crimes. For example, Zhang (2009) found that in 2003, 14 youth gangs, which involved a total of 51 members, had been convicted in the city of Ningbo in the Zhejiang province, and that by 2007 the number increased to 48, with 178 members involved.

Despite the progress in exploring gangs across the world, research on gangs in China is very limited. Even their very presence has not been subjected to any fully comprehensive analysis, making the study of their characteristics even more difficult (Liu, 2008). Delinquency rates and their correlates are also sparse and unreliable, although it has been suggested that rising expectations of living standards, growing income inequality and a relaxation in social control are behind the increase in crime (Deng \& Cordilia, 1999). It has been shown, for example, how the relaxation of state control and a growing impact of foreign cultures are linked to the rise in crime (Dutton, 1997). In light of the sweeping and tradition-defying waves of global trends, which have been associated with social adaptation struggles (Zhang, Messner, \& Liu, 2008), this research gap is clearly unjustified.

Some of the reasons behind the rise in gangs have been attributed to the Internet, which despite its censorship can still play a substantial role in spreading information on illegal activities. However, although the rapid shifts 
in social and economic conditions, globalisation and growing use of the Internet can shed some light on gangs in China (Liang \& Lu, 2010), they cannot account for the full extent of juvenile delinquency. Studies in China have suggested that more than $80 \%$ of youth offenses are gang-related (Zeng \& Xie, 2006). For example, Lin (2005) reported that 89 of the 124 juvenile cases indicted in the city of Jieyang of the Guangdong province in 2004 were gang-related. Similarly, a study of 966 juvenile offenders in the city of Beijing and the provinces of Hubei and Guizhou found that $75 \%$ of their offenses were gang-related (Yao, 2011).

Whilst there are some data on Chinese juvenile justice and delinquency, they remain largely descriptive and offer little basis for any analysis of patterns or trends (Zhang, 2008), partially because the use of self-report studies in China has been very limited. Within this limitation, however, the offending correlates of the officially recorded data of the Wuhan birth cohort of 1973, for example, were subjected to analysis. It was found that theoretically-oriented criminological covariates, like negative peer influences, troubled familial relationship, and poor school attachment and attainment could account for variability in offending (Friday, Ren, Weitekamp, Kerner, \& Taylor, 2005). Using self-reported methods in a study of middle and high school students from rural and metropolitan areas was also explored, showing that social strain, particularly among boys, was related to participation in juvenile delinquency (Bao \& $\mathrm{Pi}, 2007$ ).

Official data show that the average age of juvenile delinquents decreased from 17.6 to 15.7 years old from 1998 to 2003 (Luo, 2007). Many juvenile delinquents committed their first crime at the age of 14 and about $81 \%$ of them were involved in criminal behavior by the ages of 14 and 16 in 2007 (Luo, 2007). Case studies of youth gangs and gang-related crime also show a similar trend. For example, Fang and Feng (2013) reported a gang case cracked down by police, which involved ten teenage members who were all school drop-outs and committed 113 thefts of items, including stolen cash, cigarettes, hard liquors, laptops, digital camera and other goods.

Survey data in China have shown that rural migrants in urban areas are more likely to be involved in law-breaking behavior and children from migrant families are more likely to be involved in gang-related activities. A study in the city of Tianjin suggested that migrants are likely to be poor and reside in more deprived neighborhoods, where the cost of housing and daily expenses tends to be low (Zhang, 2004). Consequently, the children from migrants' families are unlikely to have suitable environment and financial resources in their transition to urban life, fuelling their frustration and resentfulness.

It appears that gang-related crime in China has become more serious and violent in the recent years, which is consistent with the general rise of delinquency in the whole country. As the Internet has become popular, some young people use it as a communication and connection 'vehicle' for developing and forming groups for illegal purposes (Ding \& Han, 2012; Wang \& Xia, 2009; Zhao \& Feng, 2011).

The gangs are usually territorial, identifying with the specific 'turf', and their crimes tend to be 'cafeteria-style' and not particularly serious, albeit severely punishable under the law (Zhang Ying-li, 2009). Their size is also usually quite small. For example, using data collected from offenders in Ningbo's prisons, it was found that the average size of youth gangs ranged from the size of 4.6 to 5.6 members (Zhang, 2009). Their membership also tends to be rather transitory and age-graded, while their organization seems to be rather low, with few characteristics that reflect those of more formal bodies. The mobility of their members appears to be high, so that once a criminal activity has taken place, some members may leave the gang and be replaced by new recruits.

Like most gangs, in the West, the Chinse ones typically have their own nick names, rules and codes of conduct. A survey of juveniles in a detention center in the city of Nanjing showed that when planning to commit a crime, each individual member was assigned a specific task, had to pay a membership fee and could expect a penalty if the rules were violated or when an assigned task was not performed up to the required standard (Lin, 2005).

As Chinese studies indicate, the primary goal for some young people to join gangs is to develop friendships and seek group identities for protection (Huang, 2009) as they may be rejected by their 'normal' peers and can struggle to receive full care and attention from their busy parents and even teachers. Consequently, by participating in illegal group activities a new gang member expects to be accepted and rewarded in both emotional and material terms.

In terms of international comparisons, a study using self-reported delinquency and behavior questionnaires with high school students in Los Angeles, Seoul and Tianjin found high levels of study participation across the three groups, with nearly 95\% of Chinese students completing a useable questionnaire (Greenberger, Chen, Beam, Whang, \& Dong, 2000). It revealed that Chinese and Korean students self-reported lower levels of delinquent behavior than their American counterparts. However, they were all similar in a common set of predictors, like the behavior of close friends and the sanctions close friends would impose for misconduct. 
A comparative study of self-reported behavior of high school students in Shanghai and Brisbane showed that although their levels of delinquent behavior were substantially lower in the former sample, co-offending was more common in the Shanghai sample (Wei, Homel, Prichard, \& Xu, 2004). A different comparison of school-based samples from Beijing and an urban area in the Rocky Mountain area of the US, showed that fifty-two percent of US boys and girls reported the presence of gangs in their neighbourhoods, while $49 \%$ of Chinese boys and $47 \%$ of Chinese girls reported the presence of gangs in theirs (Jessor et al., 2003). This indicates that the self-reported methodology is quite practical in the Chinese setting, and that the differences in exposure to youth gangs across US and Chinese samples may be at least somewhat comparable. It is apparent, however, that the group context and co-offending are more important correlates of juvenile offending in China than in the more individual-oriented American culture.

\section{Gang Crime in Contemporary India}

In India, the Gajuwaka police arrested three minor boys for stealing electronic goods and other valuable items, including motorbikes, from four houses at various places in the city. The trio, who all came from deprived families and were school dropouts, formed a gang and were involved in several house break-ins.

There is already a large body of research (mostly Western) on youth gangs and juvenile delinquency, but, like in China, in India they are also largely under-researched, partly because of a general lack of focus on youth as a social category. Like in China, in India, firearms are not easily available either, and they are rarely seen in the hands of youngsters who use more traditional weapons, like arson, fists, poisonous herbs, as well as blunt and sharp instruments. It appears that the first generation of gangs in India started off and built their foundations through violent crimes, such as extortion rackets and supari (contract) killings. These gangs then invested their money into subsidiary illegal businesses, such as land grab operations, betting and gambling rackets, and illicit liquor trade (Raghavan, 2010).

Some gangs also diversified into drug trafficking and fake currency rackets, flourishing during the eighties and nineties and gradually increasing their spheres of influence. They also developed contacts with legal business partners and/or invested in legal businesses, such as real estate, movies and the stock market to further tighten their grip on power. This financial power helped them to develop even closer ties with the authorities - the police, local officials and politicians who became involved in powerful cartels that are mutually beneficial to each other (Zaidi, 2012). It is also argued that the Indian mafia is heavily involved in the Mumbai-based Bollywood film industry, providing cinematic production with funds and using them as fronts for illegal activities. The connections between the Indian movie industry and criminal networks became a poorly kept secret as some of the biggest names of Bollywood could be spotted in the company of underworld figures at cricket matches and parties (Srivastava, 2003).

Being a major transit point for heroin from the Golden Triangle and Golden Crescent en route to Europe, India is also the world's largest legal grower of opium, which facilitates youth gang recruitment. The causes of increasing youth gang involvement, however, have been generally ignored by researchers in India. Importantly, around sixty percent of its people live in slums, its infrastructure is underdeveloped, with health, education and sanitation facilities out of reach for most of the population. As Mehta (2006) says, 'the real luxuries are running water, clean bathrooms, and transport and housing fit for human being. ...The greatest luxury of all is solitude' (p. 135).

According to Raghavan (2011), threefold strategy is used in India to strengthen the gang cohesion. Firstly, the need for money to maintain a certain lifestyle and the glamour associated with gangs is exploited by gang leaders to win new recruits. Money power is used to seduce the recruits into the network. The classic method involves getting them used to good food, wine and women, the assumption being that once they get used to this 'high life', their need for money would spur them on to get firmly involved in more serious gang activities. Another motivation is the need for creating a name for oneself. The thrill of knowing a bhai (don) and being in close proximity to him is sometimes enough to lure a youth into the net. A third strategy is to help young boys in prison by offering them legal aid and gradually luring them into the gang. A youth who has been arrested and is in jail for violent offences may be offered the job of a handler or work under an existing handler in the area that he hails from. Handlers also cultivate boys in areas where they live/operate and the boys who show 'daring' traits or have history of violent crimes are targeted in particular.

Although youth gangs appear to be increasing their involvement in drug trafficking in India, research has not documented extensive networks of drug trafficking as an organized activity managed exclusively by youth gangs. Like alcohol, many psychoactive substances, such as ganja or bhang, are not regarded as drugs amongst most Indian families. In other words, they are not seen as 'hard drugs', like cocaine and are sometimes even viewed as 
having medicinal, religious and spiritual properties.

Though gangs are primarily male dominated, female gang membership is on the rise. Female gang members continue to perform the traditional subordinate functions of providing financial, sexual and emotional support to the male gang members. However, there is little information on the number of women and girls involved in gang violence. It is known that many young women are suffering gang-related sexual exploitation or violence, but its extent is largely hidden, although it is estimated that a rape takes place every twenty minutes in India (Smith, 2015). It also appears that the Indian government is in denial about its rape culture as it recently banned a documentary India's daughter, which reconstructs the infamous gang rape and murder of a young woman on a bus in Delhi. Although 'all-female' gangs do exist, they are rare and seldom the focus of the police. Furthermore, law enforcement officials are less likely to recognize or stop female gang members and have more difficulty in identifying their involvement in gang-related activities.

Undoubtedly, life in India has undergone drastic changes after social and economic development in the last two centuries. Similarly to China, as a result of rapid advancement of industrial growth, there is a large-scale migration from rural to urban areas and the processes of liberalisation, privatisation and globalisation have changed social relationships almost everywhere in India. The joint family and strong social integration of youth, which was a general rule in India, now became less common. The young people are no longer under strict parental control of family members and relatives, resulting in a rise of juvenile delinquency and crime. It also appears that government responses are failing to address the needs of youths involved in gangs and that gangs cannot be studied in India by applying international standards as 'youths' are not recognized as a distinct social category in Indian research.

This relatively short review has covered some of the main themes of gang-related problems in China and India. Given the scarcity of available findings, it is inevitably far from exhaustive and should be treated as a first-step contribution to the subject that further studies may attempt to complement and cautiously theorise. Although the data from Asia is very limited, it should not deter researchers from analysing and comparing whatever little is available. Despite the issues of gang-related crime, exploitation, and children left back home with grandparents, the firmly dominant position of cities in China, and their increasingly growing influence in India, have created unprecedented opportunities for the rural migrant workers fleeing poverty and starvation in the country. The efforts geared towards exploring these and other similar challenges that will arise with the transformation of cities will likely offer a chance to help inform public policies aimed at overcoming them.

\section{References}

Bao, W. N., \& Pi, Y. (2007). An empirical test of General Strain Theory from a matching perspective in social support. International Journal of Offender Therapy and Comparative Criminology, 51, 9-24. http://dx.doi.org/10.1177/0306624X06294428

Deng, X., \& Cordilia, A. (1999). To get rich is glorious: rising expectations, declining control, and escalating crime in contemporary China. International Journal of Offender Therapy and Comparative Criminology, 43, 211-229. http://dx.doi.org/10.1177/0306624X99432008

Ding R., \& Han, H. (2012). Criminological thinking on a case of youth crime gang. Legal System and Society, 6, 66-68.

Dutton, M. (1997). The basic character of crime in contemporary China. The China Quarterly, 160-177. http://dx.doi.org/10.1017/S030574100004368X

Fang X., \& Feng, Y. (2013). Police have destroyed a juvenile burglary gang. Retrieved from http://jxxy. jxnews.com.cn/system/2013/05/16/012423362.shtml.

Friday, P. C., Ren, X., Weitekamp, E., Kerner, H. J., \& Taylor, T. (2005). A Chinese birth cohort: theoretical implications. Journal of Research in Crime and Delinquency, 42, 123-146. http://dx.doi.org/10.1177/0022 427804266561

Greenberger, E., Chen, C., Beam, M., Whang, S. M., \& Dong, Q. (2000). The perceived social contexts of adolescents' misconduct: a comparative study of youths in three cultures. Journal of Research on Adolescence, 10, 365-388. http://dx.doi.org/10.1207/SJRA1003_7

Huang, X. Y. (2009). A Study on the Psychological Mechanism of Post-1990s Gang Crime. Journal of Liaoning Police Academy, 53(1), 59-61.

Jessor, R., Turbin, M. S., Costa, F. M., Dong, Q., Zhang, H., \& Want, C. (2003). Adolescent problem behavior in China and the United States: a cross-national study of psychosocial protective factors. Journal of Research 
of Adolescence, 13, 329-360. http://dx.doi.org/10.1111/1532-7795.1303004

Liang, B., \& Lu, H. (2010). Internet development, censorship, and cyber crimes in China. Journal of Contemporary Criminal Justice, 1, 103-120. http://dx.doi.org/10.1177/1043986209350437

Lin, Y. X. (2005). Youth students gang crime research, Youth Studies, 8, 25-32.

Liu, J. (2008). Data sources in Chinese crime and criminal justice research. Law, Society and Change, 50, 131-147. http://dx.doi.org/10.1007/s10611-008-9135-3

Luo, D. H. (2007). Research on the Psychology of Criminal justice. Beijing: Mass Press.

Mehta, S. (2006). Maximum city: Bombay lost and found. New Delhi: Penguin Books.

Raghavan, V. (2010). Youth Arrested in Extortion Cases in Mumbai City: Processes of Entry and After (Doctoral dissertation) [Abstract]. Retrieved from http://shodhganga.inflibnet.ac.in/bitstream/10603/2727/6/06_abstr act.pdf

Raghavan, V. (2011). Criminal Gangs in Mumbai City: From Actor to Network Orientation. Retrieved from http://ssrn.com/abstract=2371832

Smith, J. (2015). India is in denial about its rape culture - but then so are we. The Independent. Retrieved from http://www.independent.co.uk/voices/india-is-in-denial-about-its-rape-culture--but-then-so-are-we-1009348 1.html

Srivastava, S. (2003). Analysis: Bollywood and the mafia. Retrieved from http://news.bbc.co.uk/1/hi/world/ south_asia/3152662.stm

Wang, Z., \& Xia, Q. (2009). On the research of Web sub-culture and its relationship with youth crime. The $18^{\text {th }}$ Conference of China Society of Criminology, 510-516.

Wei, Z., Homel, R., Prichard, J., \& Xu, J. (2004). Patterns of juvenile offending in Shanghai and Brisbane. Australian and New Zealand Journal of Criminology, 37, 32-51. http://dx.doi.org/10.1177/000486580403 $70 S 103$

Yao, B. (2011). Survey report on juvenile gang crime of three provinces. China youth research, 4, 40-45.

Zaidi, S. H. (2012). Dongri To Dubai: Six Decades of The Mumbai Mafia. New Delhi: Lotus Collection.

Zeng, J., \& Xie, H. D. (2006). The inspiration of the different association theory's criminal view for prevention the youngsters crime. Journal of Sichuan Police College, 18(4), 40-44.

Zhang, B. (2004). Analyses on characteristics of youth crimes in urban and rural Areas of Tianjin city in the nineties. Journal of Fujian Public Safety College, 2, 5-9.

Zhang, L. (2008). Juvenile delinquency and justice in contemporary China: a critical review of the literature over 15 Years. Crime, Law and Social Change, 50, 149-160. http://dx.doi.org/10.1007/s10611-008-9137-1

Zhang, L., Messner, S. F., \& Liu, J. (2008). A critical review of recent literature on crime and criminal justice in China: research findings, Challenges and prospects. Crime, Law and Social Change, 50, 125-130. http://dx.doi.org/10.1007/s10611-008-9134-4

Zhang, Y.-L. (2009). On the survey and analysis of 196 youth gang. Journal of Jiangsu Police Officer College, 6, 133-140.

Zhao, L., \& Feng, J. (2011). On the research of the characteristics and causes of youth gangs as well as its countermeasures in Hebei province. Journal of Hebei Youth Administrative Cadre College Journal, 6, 6-11.

\section{Copyrights}

Copyright for this article is retained by the author(s), with first publication rights granted to the journal.

This is an open-access article distributed under the terms and conditions of the Creative Commons Attribution license (http://creativecommons.org/licenses/by/3.0/) 